\title{
Ultrasound-Guided Parasternal Block Allows Optimal Pain Relief and Ventilation Improvement After a Sternal Fracture
}

Kurian P. Thomas · Shaji Sainudeen · Suraj Jose ·

Mansour Y. Nadhari · Philippe B. Macaire

Received: December 11, 2015 / Published online: March 21, 2016

(C) The Author(s) 2016. This article is published with open access at Springerlink.com

\section{ABSTRACT}

Introduction: Sternal fractures are a painful condition which can result in pulmonary morbidity if not treated promptly. The management of isolated fractures has changed from hospital to home-based treatment, provided other major injuries have been excluded. Pain management is the mainstay of treatment. In this case report, we describe how a parasternal block under ultrasound guidance for sternal fracture provided better analgesia thereby improving ventilation.

Case report: A 26-year-old man was admitted to the emergency department following a road traffic accident. His initial evaluation revealed a

Enhanced content To view enhanced content for this article go to http://www.medengine.com/Redeem/ DB44F0606B8F68B8.

Electronic supplementary material The online version of this article (doi:10.1007/s40122-016-0050-5) contains supplementary material, which is available to authorized users.

K. P. Thomas · S. Sainudeen $\cdot$ S. Jose

M. Y. Nadhari · P. B. Macaire ( $\varangle)$

Department of Anesthesiology, Rashid

Hospital-Trauma Centre, Dubai Health Authority,

Dubai, United Arab Emirates

e-mail: ph.macaire@gmail.com radio-cubital displaced fracture at the elbow level with severe tenderness over the sternum. Chest X-ray on admission did not reveal any abnormality. On preoperative checkup he was found to have altered chest mechanics with severe pain and tenderness over the sternum. Arterial blood gas (ABG) analysis showed respiratory acidosis. Pulmonary electrical impedance tomography showed hypoventilation of anterior portions of both lungs. An ultrasound examination of the sternum showed a fractured sternum with complete disjunction. An ultrasound-guided bilateral parasternal block was performed which resulted in efficient analgesia and thereby improved his ventilation as indicated by the improvement in ABG.

Conclusion: Timely and proper analgesia can reduce the pulmonary morbidity in sternal fractures. Of the various analgesic techniques, parasternal block under ultrasound guidance is a relatively simple, safe, and target-specific procedure that can provide efficient pain relief.

Keywords: Regional analgesia; Parasternal block; Pain; Sternal fracture; Ventilation improvement 


\section{INTRODUCTION}

Sternum fracture is a painful condition resulting most commonly from deceleration injury or blunt thoracic trauma. Direct impact sports, vehicle to pedestrian collision, falls, and assaults account for the remaining causes [1]. A current trend in the management of isolated sternal fractures is to discharge the patient at the earliest opportunity if electrocardiogram (ECG), echocardiography, chest computed tomography (CT) scan, and cardiac enzymes are normal [2]. Optimal analgesia is the main modality of treatment of these fractures in order to limit the development of pulmonary complications secondary to impairment of spontaneous ventilation and to allow painless noninvasive ventilation if needed.

In this case report, a prompt, timely management of pain with a simple regional analgesic technique, the parasternal block, was highlighted. Pain relief management and improvement of patient's ventilation parameters are discussed.

\section{CASE REPORT}

A 26-year-old man was admitted to the emergency department following a road traffic accident. He had a Glasgow Coma Scale score of 15. The surgeon diagnosed a radio-cubital displaced fracture at the elbow with no obvious neurologic or vascular injuries. The patient complained about chest pain rated 8 out of 10 on a visual analogue scale (VAS). On further evaluation, tenderness over the upper sternum with no ecchymosis/subcutaneous emphysema was noted. Chest X-ray at the time of admission did not reveal any abnormality. Electrocardiogram showed tachycardia. Troponin levels were within normal values. The patient received diclofenac
$75 \mathrm{mg}$ and morphine $6 \mathrm{mg}$ intravenously. The VAS score decreased to 4/10. Intravenous paracetamol $1 \mathrm{~g}$ every $6 \mathrm{~h}$ and diclofenac $75 \mathrm{mg}$ every $12 \mathrm{~h}$ were prescribed. He was posted for open reduction internal fixation of the lower third humerus electively, after $8 \mathrm{~h}$.

At the pre-operative checkup, the patient was clinically having shallow breathing, with altered chest mechanics and tachycardia. Pulse oximetry value was noted at $94 \%$ using a high concentration oxygen mask with a flow at $10 \mathrm{~L} /$ min (fraction of inspired oxygen $\left[\mathrm{FiO}_{2}\right]$ at $80 \%$ ). A severe pain with tenderness over the sternum was still present. Arterial blood gas (ABG) analysis noted an acute respiratory acidosis (Table 1). An ultrasound examination was performed, which revealed a sternal fracture between the third and fourth ribs (Fig. 1) with

Table 1 Patient's arterial blood gas values before and after parasternal block

\begin{tabular}{lll}
\hline & Pre-block & Post-block \\
\hline $\mathrm{FiO}_{2}(\%)$ & 80 & 21 \\
$\mathrm{pH}$ & 7.212 & 7.349 \\
$\mathrm{pCO}_{2}(\mathrm{mmHg})$ & 65.7 & 45.4 \\
$\mathrm{pO}_{2}(\mathrm{mmHg})$ & 62.1 & 98.4 \\
$\mathrm{pO}_{2} / \mathrm{FIO}_{2}$ & 77.6 & 488.5 \\
$\mathrm{cNa}^{+}(\mathrm{mmol} / \mathrm{L})$ & 136 & 136 \\
$\mathrm{cK}^{+}(\mathrm{mmol} / \mathrm{L})$ & 4.5 & 4.5 \\
$\mathrm{cLac}^{2}(\mathrm{mg} / \mathrm{dL})$ & 9 & 9 \\
$\mathrm{ctHb}(\mathrm{g} / \mathrm{dL})$ & 12.8 & 12.6 \\
$\mathrm{cGlu}(\mathrm{mg} / \mathrm{dL})$ & 150 & 164 \\
$\mathrm{HCO}_{3}^{-}(\mathrm{mmol} / \mathrm{L})$ & 20.2 & 25.5 \\
$\mathrm{SBEc}(\mathrm{mmol} / \mathrm{L})$ & -3.3 & -1 \\
\hline
\end{tabular}

$c G l u$ concentration of glucose, $c K^{+}$concentration of potassium, $c L a c$ concentration of lactate, $c \mathrm{Na}^{+}$ concentration of sodium, $c t H b$ concentration of total hemoglobin, $\mathrm{FiO}_{2}$ fraction of inspired oxygen, $\mathrm{HCO}_{3}{ }^{-}$ bicarbonate concentration, $\mathrm{pCO}_{2}$ partial pressure of carbon dioxide, $p \mathrm{O}_{2}$ partial pressure of oxygen, $\mathrm{SBE} c$ standard base excess (corrected) 


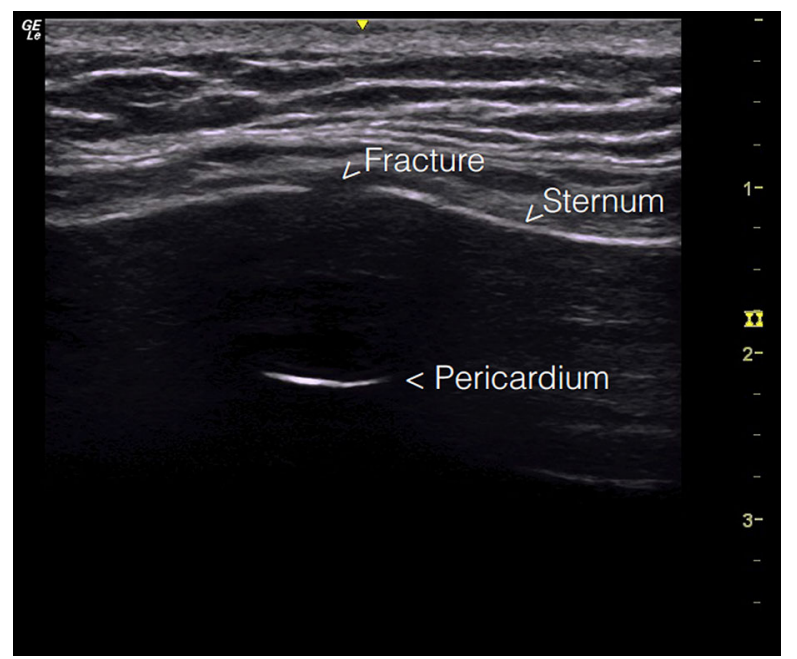

Fig. 1 Longitudinal ultrasound scan of the sternum showing the fracture with complete disjunction and visualizing the pericardium

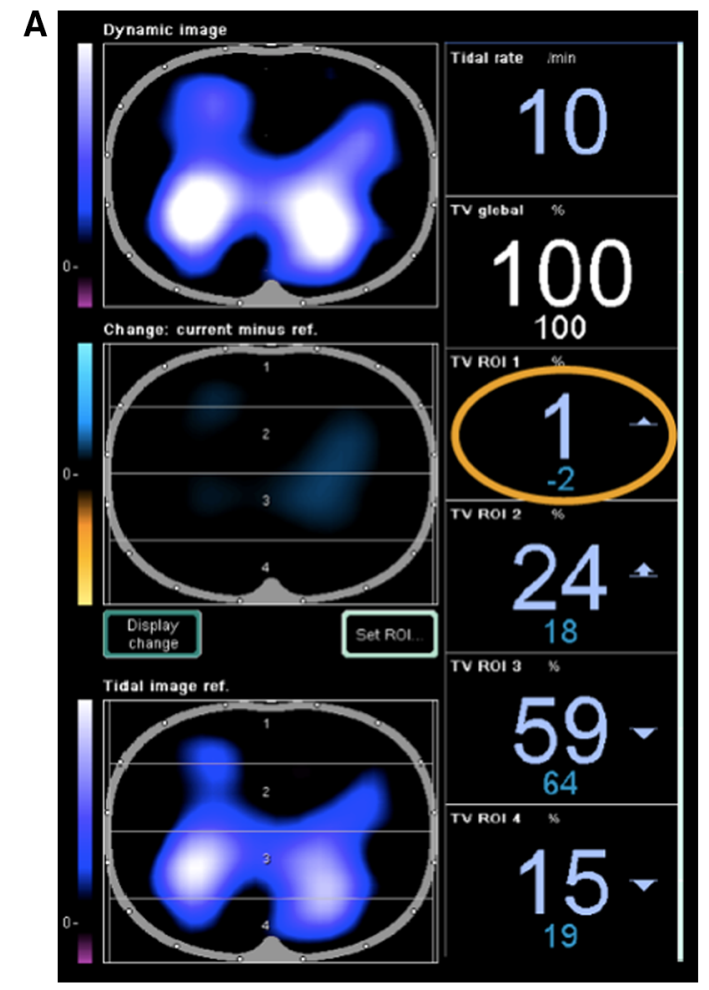

Fig. 2 Pulmonary electrical impedance tomography (EIT) monitoring of the patient. showing a hypoventilation of the anterior portions of both right and left lungs with just $1 \%$ complete disjunction, exposing the pericardium (see Video 1 in the supplementary material). The patient was connected to a pulmonary electrical impedance tomography (EIT) monitor (Pulmovista ${ }^{\circledR}$ 500, Dragger Lubeck, Germany), a noninvasive, real-time imaging modality which measures global and regional changes in lung volume at the bedside. EIT showed hypoventilation of the basal-anterior portions of both right and left lungs with just 1\% of tidal volume being distributed within these parts (Fig. 2a).

A bilateral parasternal block was performed, after obtaining the patient's informed consent, taking into consideration the post-injury pain, hypoventilation, acute respiratory acidosis, and

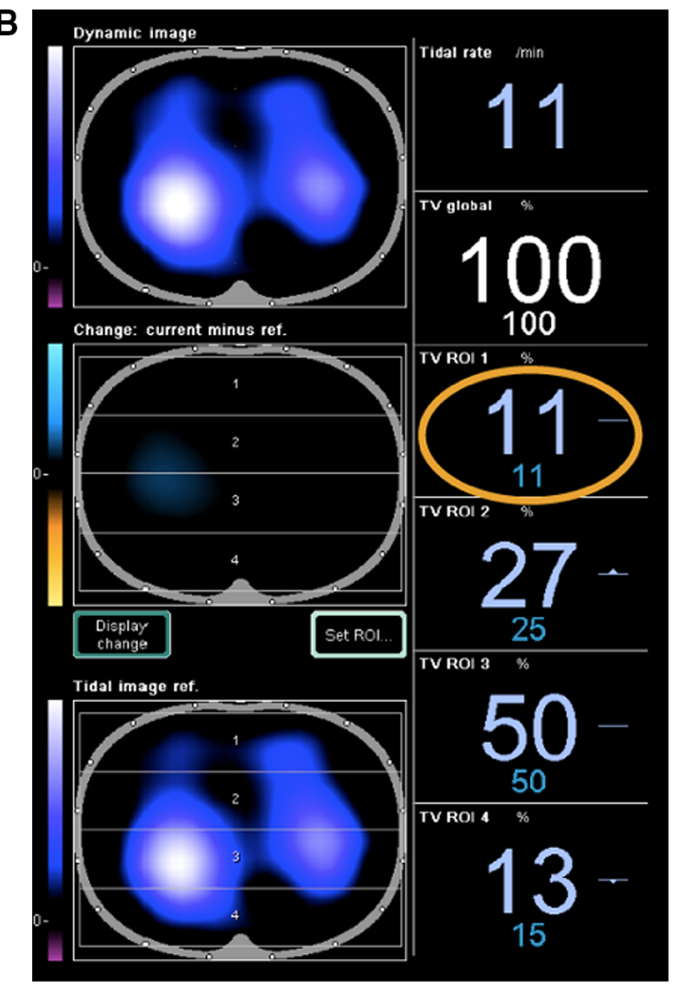

tidal volume being distributed to both anterior regions and b improved ventilation in the anterior zones (11\%) after the parasternal block 
EIT data. Blocks were performed on the lower border of the 3rd rib and upper border of the 4th rib under ultrasound guidance using a linear probe (linear 12L probe of a GE Logic E B12 ultrasound machine) (Fig. 3; see also Video 2 in the supplementary material). The ultrasound scan was performed from lateral to medial in the intercostal space. The intercostal muscles and pleura were identified along the lower border of the rib. At the lateral border of the sternum, internal thoracic vessels lying anterior to transverse thoracic muscle are identified. The needle is inserted in-plane to follow its tip perfectly to prevent pneumothorax or pericardium puncture. Four milliliters of ropivacaine $0.75 \%$ was injected beyond the internal intercostal muscles, anterior to the transversus thoracic muscle to block the terminal anterior branch of the intercostal nerve and spread to the perivascular sympathetic plexus. The collateral nerve was blocked by another injection at the upper border of the lower rib. A total volume of $16 \mathrm{~mL}$ ropivacaine $0.75 \%$ was injected $(8 \mathrm{~mL}$ on both sides). After $10 \mathrm{~min}$, the patient's clinical condition improved significantly with a pain

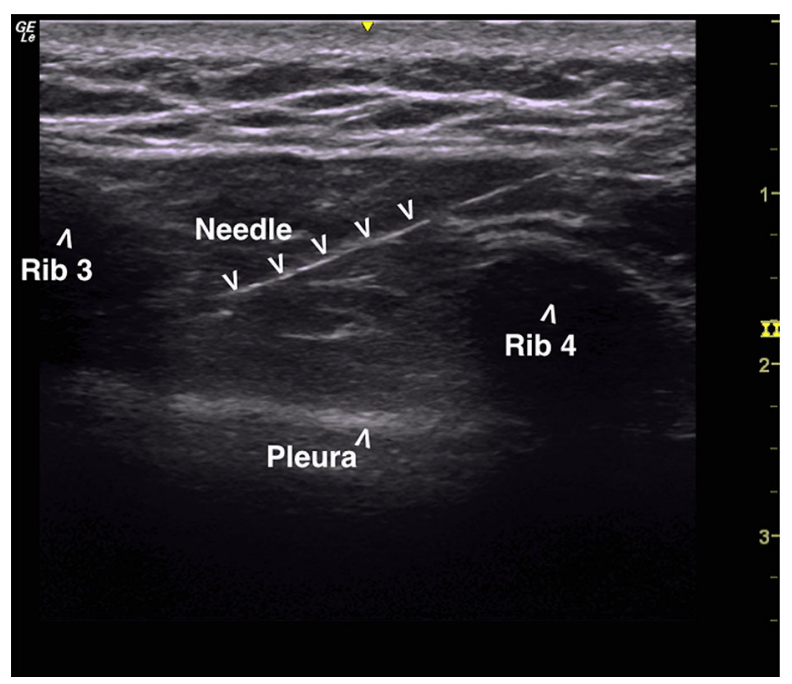

Fig. 3 Parasternal block injection of the intercostal nerve lower border of the rib lateral to the sternal border score at $0 / 10$ at rest and on sternal pressure. Pulse oximetry improved to $100 \%$ on room air and EIT showed improved ventilation in the anterior zones (from $1 \%$ to $11 \%$; Fig. 2 b). We noted a correction of the respiratory acidosis (Table 1). The patient remained comfortable till he was taken up for open reduction internal fixation of the elbow fracture, under supraclavicular brachial plexus block supplemented with general anesthesia in the prone position, $8 \mathrm{~h}$ after the parasternal block. Postoperative analgesia was maintained with paracetamol $1 \mathrm{~g}$ intravenously every $6 \mathrm{~h}$ and parecoxib $40 \mathrm{mg}$ intravenously every $12 \mathrm{~h}$. The patient remained stable in the postoperative period. On a postoperative visit, $6 \mathrm{~h}$ after the surgery, a pain score of $3 / 10$ on a VAS on sternal pressure was noted and lack of any further effect of the block was highlighted by normal sensory cutaneous testing (pin prick and cold perception). The patient remained comfortable throughout the postoperative period without any breathing difficulty. He was discharged on the second postoperative day with oral analgesics and follow-up instructions.

Informed consent was obtained from the patient for being included in this case report.

\section{DISCUSSION}

In this case report, complete pain relief after a sternal fracture was obtained with a simple bilateral parasternal block. The block improved the patient's ventilation and blood gas values with optimal pain relief during the perioperative period. To the authors' knowledge, this is the first description on the parasternal block in sternal fracture perioperative management.

Sternal fracture is a common injury often associated with fractures of vertebrae, most commonly thoracic [3, 4]. Oyetunji et al. [5] 
in an analysis of 23,985 trauma bank records in the USA reported $21.6 \%$ association with thoracic vertebra fracture and $16.9 \%$ with lumbar vertebra fractures. The overall mortality of sternal fractures is $0.7 \%$ but the mortality may increase to $10 \%$ in the presence of other associated injuries $[6,7]$. Sternocostal disruptions with minimal disruption and displacement are often missed in chest radiographs. As in our case, ultrasound diagnosis of sternal fracture is a better guide, performed quickly and accurately at the bedside $[8,9]$. Reissig et al. [10] systematically reviewed the role of ultrasound in emergencies and showed that it is a handy tool in diagnosing thoracic emergencies. Patients have post-trauma chest pain that can last for 8-12 weeks [11]. Pain can result in impaired ventilation leading to pulmonary morbidity. Management of pain is the mainstay of treatment of all sternal fractures along with adequate rest and breathing exercises. Fixation is not routinely indicated. Proper analgesia and respiratory care can reduce the early morbidity and outcome to a great extent [11, 12]. Studies on thoracic trauma with rib fractures also showed that proper analgesia can reduce the morbidity and mortality and lead to improvement in ventilatory parameters [13-15]. Systemic opioids are commonly used as first-line analgesics. They reduce pain scores and can improve vital capacity but their use can also result in respiratory depression due to central effects and/or in paradoxical breathing [16]. Thoracic epidural block and paravertebral block are also found to be effective. These blocks are more invasive and may have a higher incidence of complication when compared to intercostal block [17]. The body of the sternum is supplied largely by anterior branches of the intercostal nerves and sympathetic plexus around the internal thoracic artery. In addition, a collateral branch of an intercostal nerve which arises at the angle of the rib and runs along the upper border of the rib may also contribute to innervation. An intercostal nerve lies deep to the internal intercostal membrane and internal intercostal muscle and superficial to the innermost intercostal muscle in the subcostal groove of the corresponding rib. Anteriorly the nerve lies directly on the pleura except where transverse thoracic and internal thoracic vessels go close to the sternum (Figs. 4, 5). Anatomy explains clearly why the bilateral parasternal block is effective. The main risk of the parasternal block, which is a type of intercostal block, is pneumothorax and/or pericardial puncture due to poor imaging technique or poor visualization of needle tip during the block procedure [17]. Parasternal blocks should be done by a skilled physician using ultrasound guidance [17]. Wilson et al. [18] described

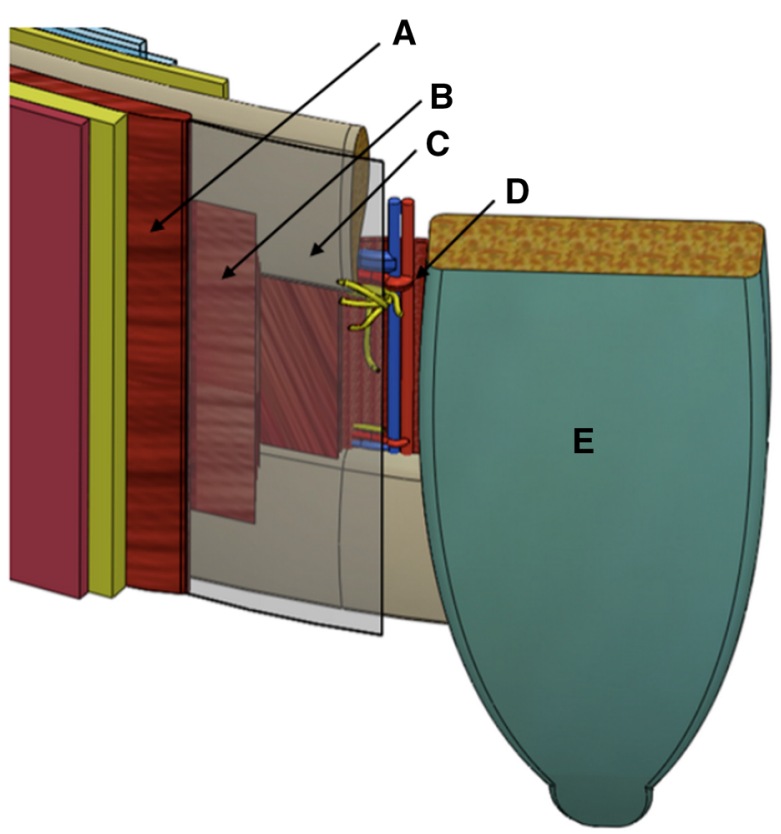

Fig. 4 Anterior view of the parasternal neuromuscular anatomy. $A$ external intercostal muscle, $B$ internal intercostal muscle, $C$ external intercostal membrane, $D$ internal thoracic artery and vein, $E$ sternum 


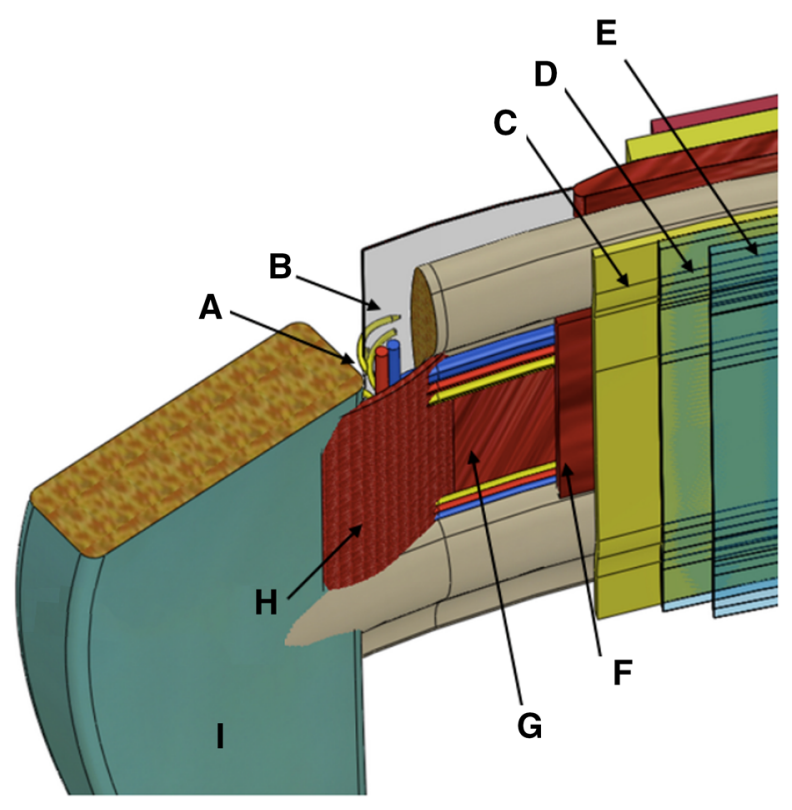

Fig. 5 Internal view of the parasternal neuromuscular anatomy. $A$ external intercostal membrane, $B$ internal thoracic artery and vein, $C$ endothoracic fascia, $D$ parietal pleura, $E$ visceral pleura, $F$ innermost intercostal muscle, $G$ internal intercostal muscle, $H$ transversus thoracis muscle, $I$ sternum

ultrasound-guided hematoma block for sternal fracture pain management and found it to be effective, but parasternal block is more target specific. Using ultrasound guidance, parasternal block is easy to perform and gives pain relief for 6-8 h. In our patient it lasted more than the expected duration. This may have been due to abolition by the block of the initial hyperalgesic response as a result of the trauma and the spread of local anesthetics to the sympathetic afferents. Studies on the effect of parasternal block for sternotomy pain after cardiac surgery reported a reduction in the postoperative opioid requirement, a facilitated early extubation, and an improvement in oxygenation in the postoperative period [19-21].

EIT was used to visualize the ventilation distribution disturbances due to the pain and the effect of the pain relief. In recent studies EIT has been of interest in elucidating the topographic distribution of tidal ventilation in different respiratory distress syndromes $[22,23]$.

Some limitations should be reported. First, because of the need for antiseptic conditions during the performance of the parasternal blockade, the electrode belt was removed and replaced. The rotation of the belt was opposite in the post-block analysis causing the dressing to prevent the electrodes from adopting the strictly same position. In an offline correction of the rotated position of the belt of electrodes, the significant changes in basal-anterior parts of the lung still remained. Secondly, despite the fact that the diaphragm movement goes distally and laterally pushing the abdomen content and the basal and lateral parts of the chest, pain-related avoidance of chest movement during inspiration and, thereby, predominance of abdominal movement might have created a general reduction of tidal volume and a disproportionate reduction in relative ventilation of the ventral lung regions (mainly related to activation of external intercostal muscles). However, these analyses will be questionable if the absolute tidal volumes were not measured.

\section{CONCLUSIONS}

In this case report, a patient with a mid-sternal fracture and disjunction benefited from a single-shot bilateral parasternal block which provided optimal pain relief and improved ventilation parameters and blood gas values.

\section{ACKNOWLEDGMENTS}

No funding or sponsorship was received for this study or publication of this article. All named authors meet the International Committee of Medical Journal Editors (ICMJE) criteria for 
authorship for this manuscript, take responsibility for the integrity of the work as a whole, and have given final approval for the version to be published.

Disclosures Philippe B. Macaire is consultant for Micrel Medical Devices and has no conflict of interest for this case report. Kurian P. Thomas, Shaji Sainudeen, Suraj Jose, and Mansour Y. Nadhari have nothing to disclose.

\section{Compliance with Ethics Guidelines Informed} consent was obtained from the patient for being included in this case report.

Open Access This article is distributed under the terms of the Creative Commons Attribution-NonCommercial 4.0 International License (http://creativecommons.org/licenses/ by-nc/4.0/), which permits any noncommercial use, distribution, and reproduction in any medium, provided you give appropriate credit to the original author(s) and the source, provide a link to the Creative Commons license, and indicate if changes were made.

\section{REFERENCES}

1. Knobloch K, Wagner S, Haasper C, et al. Sternal fractures occur most often in old cars to seat-belted drivers without any airbag often with concomitant spinal injuries: clinical findings and technical collision variables among 42,055 crash victims. Ann Thorac Surg. 2006;82:444-50.

2. Khoriati AA, Rajakulasingam R, Shah R. Sternal fractures and their management. J Emerg Trauma Shock. 2013;6:113-6.

3. Von Garrel T, Ince A, Junge A, et al. The sternal fracture: radiographic analysis of 200 fractures with special reference to concomitant injuries. J Trauma. 2004;57:837-44.

4. Cellik B, Sahin E, Nadir A, et al. Sternum fractures and effects of associated injuries. Thorac Cardiov Surg. 2009;57:468-71.
5. Oyetunji TA, Jackson HT, Obirieze AC, et al. Associated injuries in traumatic sternal fractures: a review of the National Trauma Data Bank. Am Surg. 2013;79:702-5.

6. Brookes JG, Dunn RJ, Rogers IR. Sternal fractures: a retrospective analysis of 272 cases. J Trauma. 1993;35:46-54.

7. Yeh DD, Hwabejire JO, DeMoya MA, et al. Sternal fracture-an analysis of the National Trauma Data Bank. J Surg Res. 2014;186:39-43.

8. Engin G, Yekeler E, Güloğlu R, et al. US versus conventional radiography in the diagnosis of sternal fractures. Acta Radiol. 2000;41:296-9.

9. Wook J, Dal MY, Hyun ChK, et al. Diagnostic values of sonography for assessment of sternal fractures compared with conventional radiography and bone scans. J Ultrasound Med. 2006;25:1263-8.

10. Reissig A, Copetti R, Kroegel C. Current role of emergency ultrasound of the chest. Crit Care Med. 2011;39:839-45.

11. de Oliveira M, Hassan TB, Sebewufu R, et al. Long-term morbidity in patients suffering a sternal fracture following discharge from the A and E department. Injury. 1998;29:609-12.

12. Velissaris T, Tang ATM, Patel A, et al. Traumatic sternal fracture: outcome following admission to a thoracic surgical unit. Injury. 2003;34:924-7.

13. Gage A, Rivara F, Wang J, et al. The effect of epidural placement in patients after blunt thoracic trauma. J Trauma Acute Care Surg. 2014;76:39-45.

14. Flagel BT, Luchette FA, Reed RL, et al. Half-a-dozen ribs: the breakpoint for mortality. Surgery. 2005;138:717-23.

15. Karmakar MK, Critchley LA, Ho AM, et al. Continuous thoracic paravertebral infusion of bupivacaine for pain management in patients with multiple fractured ribs. Chest. 2003;123:424-31.

16. Mackersie RC, Karagianes TG, Hoyt DB, et al. Prospective evaluation of epidural and intravenous administration of fentanyl for pain control and restoration of ventilatory function following multiple rib fractures. J Trauma. 1991;31:443-9.

17. Abrahams MS, Horn JL, Aziz MF. Evidence based medicine: ultrasound guidance for truncal blocks. Reg Anesth Pain Med. 2010;35:36-42.

18. Wilson SR, Price DD, Penner E. Pain control for sternal fracture using an ultrasound-guided hematoma block. J Emerg Med. 2010;38:359-61. 
19. Chaudhary V, Chauhan S, Choudhury M, et al. Parasternal intercostal block with ropivacaine for postoperative analgesia in pediatric patients undergoing cardiac surgery: a double-blind, randomized, controlled study. J Cardiothorac Vasc Anesth. 2012;26:439-42.

20. Barr AM, Tutungi E, Almeida AA. Parasternal intercostal block with ropivacaine for pain management after cardiac surgery: a double-blind, randomized, controlled trial. J Cardiothorac Vasc Anesth. 2007;21:547-53.

21. McDonald SB, Jacobsohn E, Kopacz DJ, et al. Parasternal block and local anesthetic infiltration with levobupivacaine after cardiac surgery with desflurane: the effect on postoperative pain, pulmonary function, and tracheal extubation times. Anesth Analg. 2005;100:25-32.

22. Mauri T, Bellani G, Confalonieri A, Tagliabue P, et al. Topographic distribution of tidal ventilation in acute respiratory distress syndrome: effects of positive end-expiratory pressure and pressure support. Crit Care Med. 2013;41(7):1664-73.

23. Blankman P, Hasan D, van Mourik MS, Gommers D. Ventilation distribution measured with EIT at varying levels of pressure support and neurally adjusted ventilatory assist in patients with ALI. Intensive Care Med. 2013;39(6):1057-62. doi:10. 1007/s00134-013-2898-8. 